Revista Brasileira de Farmacognosia Brazilian Journal of Pharmacognosy 22(1): 94-101, Jan./Feb. 2012

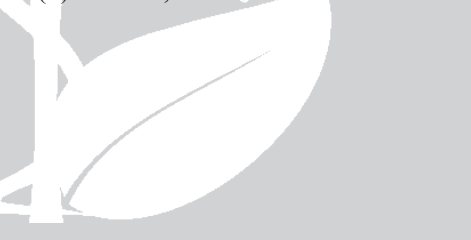

Article

Received 24 Mar 2011

Accepted 3 Aug 2011

Available online 1 Nov 2011

Keywords:

anticoagulant activity

antioxidant activity

seagrass

sulfated galactans

ISSN 0102-695X

http://dx.doi.org/10.1590/S0102-

695X2011005000199

\section{Biological activities of the sulfated polysaccharide from the vascular plant Halodule wrightii}

\author{
Juliana M. C. Silva, ${ }^{\S, 1}$ Nednaldo Dantas-Santos, ${ }^{\S, 1}$ Dayanne L. \\ Gomes, ${ }^{1}$ Leandro S. Costa, ${ }^{1}$ Sara L. Cordeiro, ${ }^{1}$ Mariana S. S. P. \\ Costa, ${ }^{1}$ Naisandra B. Silva, ${ }^{2}$ Maria L. Freitas, ${ }^{2}$ Katia Castanho \\ Scortecci, ${ }^{3}$ Edda L. Leite, ${ }^{4}$ Hugo A. O. Rocha ${ }^{*}, 1$
}

\author{
${ }^{1}$ Laboratório de Biotecnologia de Polímeros Naturais, Departamento de Bioquímica, \\ Universidade Federal do Rio Grande do Norte, Brazil, \\ ${ }^{2}$ Laboratório de Histologia, Departamento de Morfologia, Universidade Federal do \\ Rio Grande do Norte, Brazil, \\ ${ }^{3}$ Departamento de Biologia Celular e Genética, Universidade Federal do Rio \\ Grande do Norte, Brazil, \\ ${ }^{4}$ Laboratório de Glicobiologia Vegetal, Departamento de Bioquímica, Universidade \\ Federal do Rio Grande do Norte, Brazil.
}

\begin{abstract}
A sulfated polysaccharide (SPSG) was successfully isolated from seagrass Halodule wrightii Asch., Cymodoceaceae, and its antioxidant and anticoagulant activities were investigated. The data presented here showed that the SPSG is a $11 \mathrm{kDa}$ sulfated heterogalactan with a sulfatation degree of $20.63 \%$ and it also contains glucose and xylose. SPSG antioxidant activities were evaluated using several in vitro assays and the anticoagulant activity was evaluated by aPTT and PT tests. These assays suggested that the SPSG possessed remarkable antioxidant properties in different in vitro assays and an outstanding anticoagulant activity 2.5-fold higher than that of heparin Clexane ${ }^{\circledR}$ in the aPTT test. This data represents the first reported on the sulfated polysaccharide biological activities from seagrass. These results indicate that SPSG can be considered in the future as a drug utilized in treating diseases from these systems.
\end{abstract}

\section{Introduction}

Sulfated polysaccharides (SP) are compounds which posses several biological activities like as anticoagulant, antiviral, antioxidant, antitumor, antiprotozoal, anti-inflammatory, anticomplementary, antipeptic (Nader et al., 2004, Costa et al., 2010, Pomin, 2010). They occur in a great variety of animals, including the sulfated glycosaminoglycans found in vertebrates and invertebrates animals (Nader et al., 2004). Furthermore, marine invertebrate species are also rich sources of sulfated polysaccharides with novel structures such as sulfated fucans and galactans (Pomin, 2010). To the best of our knowledge, there are no data about the presence of SP in land plants, fungi or virus and few reports about sulfated polysaccharides synthesized for bacteria. Thus, besides the animals, the seaweeds are the only significant sources of sulfated polysaccharides.

Seaweed is a term used to define a group of the largest and most complex marine multicellular algae. They are divided into Rhodophyceae (red seaweed), Chlorophyceae (green seaweed), and Phaeophyceae. In the system of Simpson \& Roger (2004), green and red seaweed belongs to Plantae kingdom whereas brown seaweed belongs to Chromalveolata kingdom (Phylum Stramenopiles). However, other studies suggest red and brown seaweeds belong to other kingdoms. As of June 2011, the situation appears unresolved.

The authors are in agreement that seaweed are not vascular plants, they are photosynthetic organisms like plants which their tissues are not organized into the many distinct organs found in plants, and they synthesize sulfated polysaccharides. The well-known SP from red seaweed are sulfated galactans (Souza et al., 2007). SP from brown algae are homo- and heteropolysaccharides containing $\alpha$-L-sulfated fucose called fucan and fucoidan, respectively (Jiao et al., 2011). SP from green seaweed are usually heteropolysaccarides that contain xylose, galactose, arabinose, mannose, 
glucuronic acid or glucose (Mao et al., 2009).

In 2005, another group of organisms which synthesize sulfated polysaccharides was discovery; the angiosperms seagrass. They are vascular plant which grow in sea water and survive the tides unscathed. These flowering plants live in the coastal waters of most of the worlds'continents. In fact, to the best of our knowledge, the presence of sulfated polysaccharide was carried out only in three species of seagrass (Ruppia maritima, Halodule wrightii, and Halophila decipiens). However, only the SP synthesize for $R$. maritime was purified and its structure was suggested. It is a sulfated homogalactan composed for a regular repeating unit: $\left[3-\beta-\mathrm{D}-\mathrm{Gal}-2\left(\mathrm{OSO}_{3}\right)-1 \rightarrow 4-\alpha-\mathrm{D}-\mathrm{Gal}-1 \rightarrow 4-\alpha-\mathrm{D}-\mathrm{Gal}-\right.$ $\left.1 \rightarrow 3-\beta-\mathrm{D}-\mathrm{Gal}-4\left(\mathrm{OSO}_{3}\right)-1 \rightarrow\right]$. This SP was found in the plant cell walls, mostly in rhizomes and roots (Aquino et al., 2005). Since salt intolerant plants do not contain SP, it was suggested a possible correlation between the presence of these compounds and seagrass salt tolerance (Aquino et al., 2011). Although, SP have are described as bioactive compounds, there no data about biological activities of seagrass SP.

Heparin (a glycosaminoglycan extracted from porcine tissues) has been the most commonly used antithrombotic drug. However, it has been reported that the use of heparin may be accompanied by side effects such as bleeding complications (Nader et al., 2004). Due to the heparin side effects, antithrombotic/ anticoagulant activities of SP from several sources have been investigated, including from seaweeds (Mao et al, 2009; Camara et al., 2011).

In the past decade, the search for natural antioxidant compounds has gained considerable attention and the number of publications on antioxidants and oxidative stress has nearly quadrupled (Costa et al., 2010). Antioxidant compounds play an important role against various diseases, e.g., chronic inflammation, atherosclerosis, cancer and cardiovascular disorders, and ageing processes (Barnham et al., 2004). Due to this, these compounds have had commercial potential in medicine, food production, and the cosmetic industry. In recent years, SP have been demonstrated to play an important role as free-radical scavengers and antioxidants for the prevention of oxidative damage in living organisms (Hu et al., 2010).

The structure of sulfated polysaccharides varies according to the source (Nader et al., 2004; Pomin, 2010; Magalhaes et al., 2011). Thus, each new sulfated polysaccharide purified from new source is a new compound with unique structures and, consequently, with potential novel biological activities. There are no data about the biological activities of sulfated polysaccharides from the vascular plants. In order to determine whether sulfated polysaccharides from seagrass show biological activities, we extracted these molecules from the seagrass Halodule wrightii, and the chemical composition, anticoagulant, and antioxidant activities of this polymer were evaluated.

\section{Material and Methods}

\section{Materials}

Chondroitin-6-sulfate, dermatan sulfate, heparan sulfate, fucoidan (a homofucan from Fucus vesiculosus), xylose, fucose, glucose, manose, galactose, arabinose, fructose, glucuronic acid, ferrozin, nitrotetrazolium blue chloride, and 1,3 diaminopropane were purchased from Sigma Chemical Co. (St Louis, USA). Acetone, $\mathrm{KBr}$, entellan, and sulfuric acid were obtained from Merck (Darmstadt, Germany). Clexane ${ }^{\circledR}$ (enoxaparine) was purchased from Sanofi-Aventis Farmacêutica Co. (São Paulo, Brazil). Agarose lowMR was purchased from Biorad. Richmond, CA. DPPH (2,2-diphenyl-1-picrylhydrazyl) and sodium salicylate were purchased from Fluka (Seelze, Germany). Gallic acid was obtained from Nuclear (São Paulo, Brazil), and slides were obtained from Bioslide (São Paulo, Brazil).

\section{Plant material}

The seagrass Halodule wrightii Asch., Cymodoceaceae, was harvested on the coast of Guamare-RN, Brazil and identified by Dr. José Rubens Pirani (Department of Botany, Universidade de São Paulo).

\section{Extraction of sulfated polysaccharides from seagrass} Halodule wrightii

In order to obtain a sulfated polysacchariderich fraction, the plant material was submitted to an extraction method as described by Almeida-Lima et al. (2011). After, the sulfated polysaccharide-rich fraction was treated with trichloroacetic acid $\left(10 \%, 4{ }^{\circ} \mathrm{C}\right)$ to eliminate the protein content. The polysaccharide was then collected by centrifugation at $10000 \mathrm{x} g$ for $15 \mathrm{~min}$ and dried under vacuum. The sulfated polysaccharide was further purified by molecular sieving in Sephadex G-75 $(120 \times 1.8 \mathrm{~cm})$. About $50 \mathrm{mg}$ of polysaccharide, dissolved in $2 \mathrm{~mL}$ of water, was applied to the column, eluted with a solution of $0.2 \mathrm{M}$ acetic acid and $6 \mathrm{M}$ urea; fractions of $1 \mathrm{~mL}$ were collected and assayed by the phenol- $\mathrm{H}_{2} \mathrm{SO}_{4}$ reaction (Dubois et al., 1956). The fractions containing polysaccharide were pooled, dialyzed against water $(10 \mathrm{~L})$ for $12 \mathrm{~h}$. This step was repeated three times more. After, they were lyophilized, and suspended in distilled water for subsequent analysis. 


\section{Chemical analyses}

The monosaccharide composition, sulfate, uronic acid, protein content, and total sugar were determined as described by Rocha et al. (2005). The total polyphenolic content of samples was investigated according to previous studies (Costa et al., 2010) and a gallic acid standard curve was obtained for the calculation of phenolic content.

\section{Agarose and polyacrylamide gel electrophoresis}

The SPSG was also analyzed by agarose gel electrophoresis as described previously (Dietrich \& Dietrich, 1976). The molecular weight of the SPSG was estimated by PAGE in comparison with the electrophoretic mobility of standard compound as described previously (Pomin et al., 2005).

\section{Fourier transforms spectra (FT-IR)}

The SPSG (10 mg) was mixed thoroughly with dry potassium bromide. A pellet was prepared and the infrared spectrum was measured using a Thermo Nicolet Nexus spectrometer instrument.

\section{Histological analysis}

Samples of the seagrass were collected in the same area described, transported to the laboratory in plastic bags with river water, and cleaned of other organisms. Fragments of $5 \mathrm{~mm}$ diameter were cut from the seagrass and were immediately fixed in $70 \%$ F.A.A.; they were then conserved in $70^{\circ} \mathrm{GL}$ ethanol, submitted to dehydration, and embedded in paraffin wax according to the usual techniques utilized in plant anatomy. Sections $(5 \mu \mathrm{m})$ were obtained in a microtome (Spencer, AO Company, New York, USA) and stained with $1 \%$ toluidine blue (Sigma), $\mathrm{pH} 4.4$, for $3 \mathrm{~min}$ at $40{ }^{\circ} \mathrm{C}$. This stain indicates the presence of sulfated polysaccharides by metachromasia. The slides of the three compartments of the seagrass were observed using a Nikon Eclipse, and digital images were acquired using the software Image Pro Plus.

\section{Antioxidant activity in vitro}

The antioxidant activity of SPSG was carried out using several in vitro assays: total antioxidant capacity, DPPH free-radical scavenging activity, power reducing, superoxide radical scavenging and hydroxyl radical scavenging assays, and ferric chelating, as described earlier (Costa et al., 2010; Camara et al., 2011).

\section{Anticoagulant activity}

All the Prothrombin Time (PT) and Activated Partial Thromboplastin Time (aPTT) coagulation assays were performed with a coagulometric as described earlier (Costa et al., 2010) and the anticoagulant activity was measured using citrate-treated normal human plasma. All assays were performed in duplicate and repeated at least three times on different days $(n=6)$.

\section{Statistical analysis}

All data were expressed as mean \pm SD. Statistical analysis was done by one-way ANOVA using the SIGMAStat version 2.01 computer software. Student-Newmans-Keuls post-tests were performed for multiple group comparison. In all cases statistical significance was set at $p<0.05$.

\section{Results}

Extraction and physical and chemical properties of sulfated polysaccharide from seagrass (SPSG)

A sulfated polysaccharide-rich fraction from the seagrass Halodule wrightii (SPSG) was obtained using a methodology that combined proteolysis and methanol precipitation. This fraction showed high content of protein (data not shown); thus, we used trichloroacetic acid to eliminate this contaminant. The sulfated polysaccharide from this fraction was further purified by molecular exclusion chromatography. A single peak was observed containing polysaccharide which was eluted at the end stage of the chromatography, indicating the molecular mass at $\sim 11 \mathrm{kDa}$. This molecular mass was confirmed by SDS PAGE (data not shown).

The chemical composition of the SPSG is shown in Table 1. This polymer showed galactose, glucose, xylose, and sulfate at the same molecular ratio. In addition, the SPSG showed low levels phenol contaminants.

Table 1. Chemical analyses and molar relation of the sugar and sulfate content of SPSG.

\begin{tabular}{|c|c|c|c|c|c|c|c|c|c|}
\hline \multirow{2}{*}{ Sample } & \multirow{2}{*}{$\begin{array}{c}\text { Molecular } \\
\text { weight (KDa) }\end{array}$} & \multirow{2}{*}{ Phenolics (\%) } & \multirow{2}{*}{ Total sugar $(\%)$} & \multirow{2}{*}{ Proteins (\%) } & \multirow{2}{*}{$\mathrm{SO}_{3} \mathrm{Na}(\%)$} & \multicolumn{4}{|c|}{ Molar Ratio } \\
\hline & & & & & & $\mathrm{Gal}^{1}$ & $\mathrm{Glc}^{1}$ & $\mathrm{Xy} 1^{1}$ & $\mathrm{SO}_{3} \mathrm{Na}$ \\
\hline SPSG & 11.0 & $<0.3$ & 59.0 & nd & 20.6 & 0.9 & 1.0 & 1.0 & 1.0 \\
\hline
\end{tabular}


The FT-IR spectrum (Figure 1) showed that the major absorption bands were observed at $3415 \mathrm{~cm}^{-1}$ (O-H stretching), $1043 \mathrm{~cm}^{-1}$ (hemiacetal stretching), and $1252 \mathrm{~cm}^{-1}(\mathrm{~S}=\mathrm{O}$ asymmetric stretching). The band close to $825 \mathrm{~cm}^{-1}$ could be assigned to the sulfate group in the axial position of the C-6 of galactose. The band around $1650 \mathrm{~cm}^{-1}$ was due to the bound water.

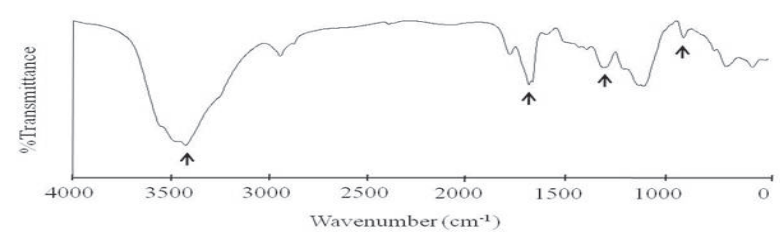

Figure 1. FT-IR spectra of the SPSG. The arrows indicate absorption bands at $3415 \mathrm{~cm}^{-1}, 1650 \mathrm{~cm}^{-1}, 1252 \mathrm{~cm}^{-1}$, and 825 $\mathrm{cm}^{-1}$.

\section{Tissue localization of SPSG}

The SPSG (Figure 2) was mostly localized in the plant cell wall, like the sulfated polysaccharides from marine algae. High amounts of the SPSG were detected in the roots of the seagrass as indicated by the arrows in the epidermal region (Figure 1C) and a low proportion in the stalks and leaves as demonstrated by the low staining intensities in the microscopy experiments (Figure 2A and 2B).

\section{Antioxidant activity from SPSG}

Seagrasses inhabit primarily intertidal areas, a harsh environment where they are subjected to repeated immersion and emersion due to tidal fluctuations. As a result, they are exposed twice daily to a wide range of environmental stress, including exposure to ultraviolet radiation, rapid temperature fluctuations, osmotic stress, and desiccation. Some of these factors contribute to free radical generation. However, these organisms have not serious damage in the presence of these reactive species, indicating that they possess protective mechanisms mediated by enzymes or antioxidant compounds. Corroborating these data, several sulfated polysaccharides from marine organisms have been recently described as potential antioxidant compounds (Costa et al., 2010; Camara et al., 2011). Thus we have evaluated the antioxidant activity of SPSG.

Antioxidants are compounds that can prevent biological and chemical substances from radicalinduced oxidation damage. Because radical oxidation of substrates occurs through a chain reaction that includes three stages (i.e. initiation, propagation and termination), antioxidants show their effects through various mechanisms. Thus, we have used different methods that can evaluate the polysaccharide effects in initiation (total antioxidant and DPPH-scavenging capacities and reducing power), propagation (ferric chelating) and termination (superoxide and hydroxil radical scavenging activities) stages.

In the total antioxidant activity assay, the SPSG presented the ability to reduce Mo (VI) to form a green phosphate/Mo (V) complex total. However, it presented the lowest activity with 15.21 ascorbic acid equivalents.

Figure 3A shows the DPPH-scavenging activity of the SPSG at various concentrations. The SPSG scavenged the DPPH radical over $41.4 \%$ at 500 $\mu \mathrm{g} / \mathrm{mL}$ and the scavenging pattern observed was dosedependent. The reducing power of the SPSG is shown
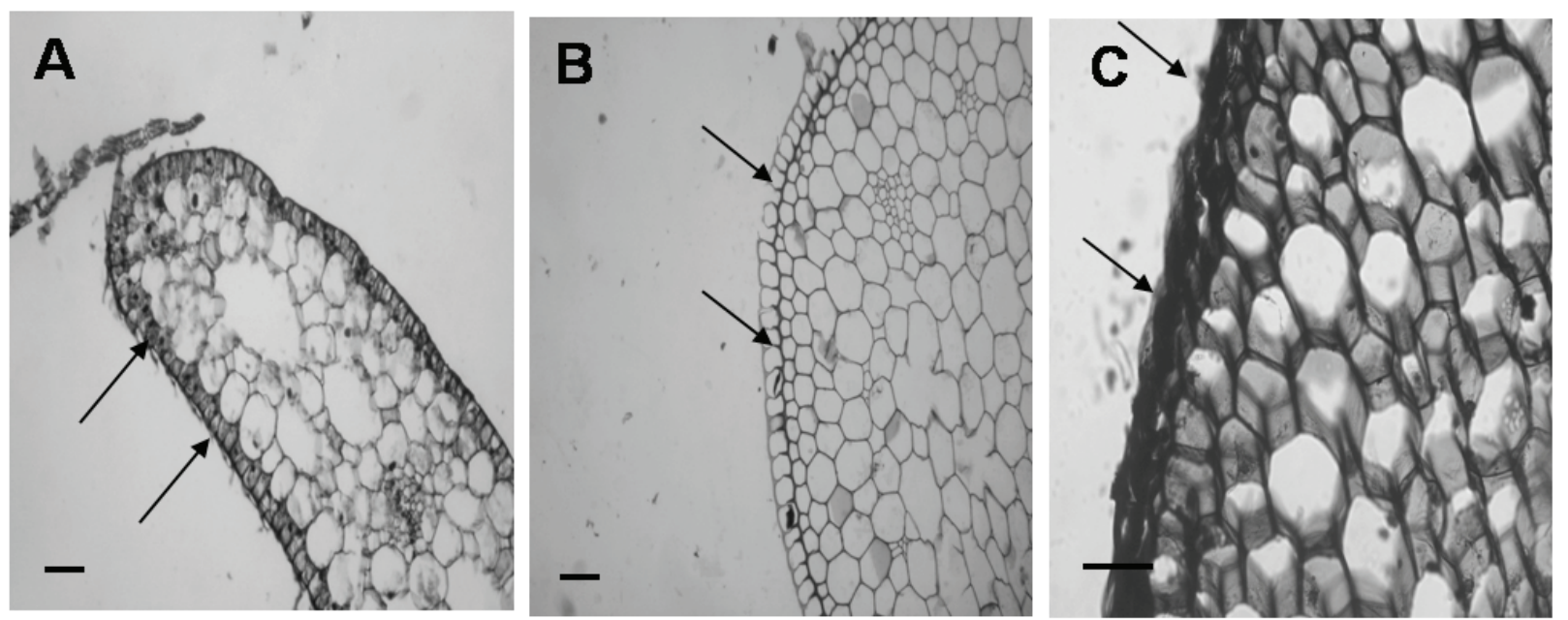

Figure 2. Sulfated polysaccharide localization in different regions of the seagrass determined by histological analysis. Optical microscopy images of the leaf (A), stem (B) and root (C) of the seagrass show differences in the metachromasia intensity of toluidine blue represented for the arrows. Original magnification was 200 for images (A, B) and 400 for image C. The bar represents $50 \mu \mathrm{m}$. 
in Figure 3B. The SPSG showed a dose-dependent antioxidant effect, reaching saturation at around 0.25 $\mathrm{mg} / \mathrm{mL}$. This experiment also showed that in order to obtain the higher reducing power of the SPSG equivalent to $50 \%$ of ascorbic acid, the required concentration of this compound was only 2.5 -fold higher than that of vitamin C. The capacity of the SPSG to scavenge superoxide radicals was confirmed when these radicals were generated in a Riboflavin-NBT-Light system (Figure 3C). The scavenging activity of the SPSG was not dose-dependent. Also, at the concentration of 0.005 $\mathrm{mg} / \mathrm{mL}$ the SPSG activity was 3-fold higher than gallic acid.
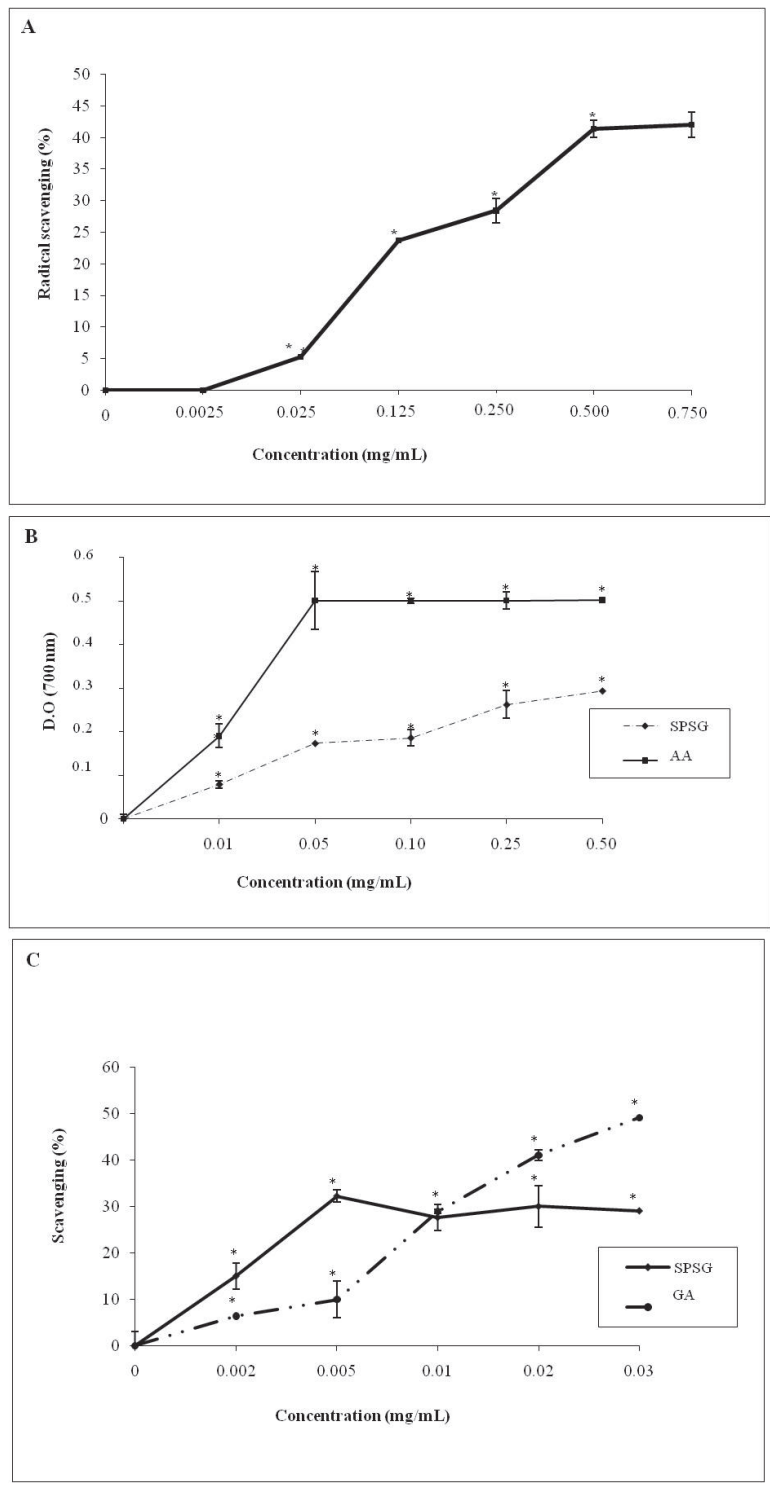

Figure 3. Antioxidant activity of SPSG. The scavenging effect of SPSG of the DPPH radical (A). Reducing power of SPSG (B). Superoxide radical scavenging activity of SPSG (C). Values are means $\pm \operatorname{SD}(n=9)$ and followed by the TukeyKramer test. *Differences were considered to be statistically significant if $p<0.05$. AA: ascorbic acid; GA: gallic acid.
The SPSG (ranging from 0.001 to $1000 \mathrm{mg} /$ $\mathrm{mL}$ ) showed neither hydroxyl radical scavenging activity nor ferric chelating activity (Data not shown).

\section{Anticoagulant activity from SPSG}

The anticoagulant activity is a well-known effect of sulfated polysaccharides in general. Here, we evaluated the anticoagulant activity of SPSG using aPTT and PT tests, which evaluate the intrinsic and extrinsic pathway of the coagulation, respectively.

No anticoagulant activity was found when the PT test was used. However, the SPSG showed strong anticoagulant activity in the aPTT test, indicating that the SPPG acts in the intrinsic coagulation pathway. To prolong the coagulation time to double baseline value in the aPTT, the required concentration of the SPSG and LMW heparin Clexane ${ }^{\circledR}$ was 20.0 and 8.0, respectively. Thus, to prolong the coagulation time to double baseline value in the aPTT, the required concentration of the SPSG was 2.5-fold higher than LMW heparin Clexane ${ }^{\circledR}$ (Table 2).

Table 2. Anticoagulant activity of SPSG of Halodule wrightii and LMW heparin Clexane ${ }^{\circledR}$.

\begin{tabular}{|c|c|c|c|}
\hline \multirow{2}{*}{\multicolumn{2}{|c|}{ Compound }} & \multicolumn{2}{|c|}{ Test } \\
\hline & & PT (s) & aPTT (s) \\
\hline \multirow[t]{4}{*}{ Control $^{a}$} & & $12.2 \pm 03$ & $31.5 \pm 0.8$ \\
\hline & $2.5 \mu \mathrm{g}$ & $11.2 \pm 0.8$ & $32.4 \pm 1.2$ \\
\hline & $5.0 \mu \mathrm{g}$ & $12.3 \pm 0.1$ & $32.2 \pm 0.7$ \\
\hline & $10 \mu \mathrm{g}$ & $12.9 \pm 0.5$ & $49.2 \pm 2.7$ \\
\hline \multirow[t]{3}{*}{ SPSG } & '20 $20 \mathrm{~g}$ & $11.4 \pm 0.4$ & ${ }^{*} 63,2 \pm 3.7$ \\
\hline & $40 \mu \mathrm{g}$ & $11.9 \pm 0.3$ & ${ }^{\#} 123.5 \pm 1.7$ \\
\hline & $80 \mu \mathrm{g}$ & $12.0 \pm 0.9$ & $\#>240$ \\
\hline Clexane $^{\mathbb{R}}$ & ${ }^{\mathrm{b}} 8.0 \mu \mathrm{g}$ & - & ${ }^{\#} 66.2 \pm 2.7$ \\
\hline
\end{tabular}

The data are the mean values of six determinations $\pm \mathrm{SD}$; \#values were considered significant with $p<0.05$; ${ }^{\mathrm{a}}$ control sample without polysaccharide. ${ }^{b}$ mass needed $(\mu \mathrm{g})$ to double the normal time of coagulation.

\section{Discussion}

We obtained a $11 \quad \mathrm{kDa}$ sulfated heteropolysaccharide composed of glucose:xylose:galactose $(1: 1: 0.9)$ from the seagrass Halodule wrightii Asch., Cymodoceaceae. Another study had shown that the seagrass Ruppia maritime synthesized homopolysaccharides composed of sulfated $\beta$-galactan (Aquino et al., 2005). These findings led us to suggest that the mechanism of production of sulfated polysaccharides of seagrass is similar to that found in green algae, which can synthesize sulfated heteropolysaccarides that contain xylose, galactose, 
arabinose, mannose, glucuronic acid, and/or glucose (Matsubara et al., 2001) and homopolysaccharides as homogalactan (Farias et al., 2008), varying their composition according to the species. This result is not surprising since some studies have shown that higher plants have a higher phylogenetic relationship with green algae than with other groups of marine algae (Pomin, 2010).

The FT-IR spectrum showed that the major absorption bands were observed at $3415 \mathrm{~cm}^{-1}(\mathrm{O}-\mathrm{H}$ stretching), $1047 \mathrm{~cm}^{-1}$ (hemiacetal stretching), and 1252 $\mathrm{cm}^{-1}$ ( $\mathrm{S}=\mathrm{O}$ asymmetric stretching). The band close to $825 \mathrm{~cm}^{-1}$ could be assigned to the sulfate group in the axial position of the C-6 of galactose (Hirst et al., 1965; Mazumder et al., 2002). This result is consistent with that of Mourão and colleagues, who showed that algae and marine angiosperms have a tendency to present sulfate group in the C-2 or C-6 (Pomin, 2010).

Seaweed sulfated polysaccharides appear to play a role in the algal cell wall organization and could be involved in the cross-linkage of other polysaccharides as cellulose, selecting the molecules that enter in the cells and also maintaining the ion balance between cytoplasm and the environment (Aquino et al., 2005). Histochemical analyses have shown that the SPSG is located mainly in the plant cell wall of root from Halodule wrightii, which suggests that the physiological properties of the SPSG are the same as those of sulfated polysaccharides from seaweeds. These data are in agreement those observed by Aquino et al. (2005) who demonstrated that sulfated galactan from the seagrass Ruppia maritima is localized in the plant cell walls, mostly in rhizomes and roots, indicative of a relationship with the absorption of nutrients and of a possible structural function. However, little is known about the role of sulfated polysaccharides in seagrass and further investigation could define the physiological properties of sulfated polysaccharide in these plants.

SPSG showed 15.21 ascorbic acid equivalents. In a previous study using sulfated polysaccharides from seaweeds Padina tetrastomatica and Turbinaria conoides, Chandini et al. (2008) found 9.79 and 9.65 $\mathrm{mg} / \mathrm{g}$ of ascorbic acid equivalent, respectively, which was considered an elevated total antioxidant capacity. Thus, the values detected here for sulfated polysaccharides from $H$. wrightii are extremely interesting, leading us to further testing of different antioxidant assays to determine their possible antioxidant mechanisms.

The ability of the SPSG in the reducing power assay was only 3 -fold weaker than L-ascorbic acid at $0.05 \mathrm{mg} / \mathrm{mL}$. However, L-ascorbic acid loses its activity at higher concentrations, which may reduce its benefits when used as a food supplement and/or antioxidant drug. Zhang et al. (2010) showed that acetylated polysaccharides with high donating-hydrogen abilities showed excellent reducing power, and in sulfated polysaccharides, the presence of the sulfate groups lead to the diminution of hydroxyl groups, which resulted in the descent of the reducing power, which may explain the lower SPSG reducing power activity compared to vitamin C. However, this SPSG activity was higher than the sulfated polysaccharide from green algae reported in the literature, the Ulvan, a sulfated polysaccharide purified from Ulva lactuta (Qi et al., 2006). It has been previously reported that there was a direct correlation between antioxidant activities and reducing power of polysaccharide. The reducing activities were usually related to the development of reductones. Reductones were reported to be terminators of free radical chain reactions by donating a hydrogen atom. In most cases, irrespective of the stage in the oxidative chain in which the antioxidant action is assessed, most nonenzymatic antioxidative activity is mediated by redox reactions (Costa et al., 2010). This led us to suggest that SPSG act as reductone and seagrass may be a better source of natural antioxidants than green algae; however, more studies are necessary.

In hydroxyl scavenging assay and ferrous chelating, no activity was found, although, this result is similar to the most of sulfated polysaccharides reported in literature that displayed very low activity in these assays (Magalhães et al., 2011). However, sulfated heterofucans from Padina gymnospora (Souza et al., 2007), as well as, sulfated homofucans from Fucus vesiculosus and Laminaria japonica (Souza et al., 2007; Wang et al., 2008), have high activity as hydroxyl radical scavengers.

The superoxide radical scavenging of the SPSG was not dose-dependent in the tested system. However, in low concentrations $(0.005 \mathrm{mg} / \mathrm{mL})$, the SPSG showed better superoxide scavenging than gallic acid, the positive control. This finding is interesting since SPSG might be effective even in low concentrations when used in the processed and/or functional food and pharmaceutical and/ or chemical industries.

Antioxidant effects of SPSG were evaluated in a comprehensive manner employing a variety of in vitro methods. We found that SPSG was active in scavenging DPPH and superoxide radicals as well in reducing power assay. Thus, SPSG probably have antioxidant action by breaking the free radical chain by donating a hydrogen atom. The antioxidant potential of SPPG can be attributed to the fact that the seagrass such as seaweeds are located in intertidal region, therefore, they are exposed to not only wide-variations in photosynthetically available radiation $(400-700 \mathrm{~nm})$ and more specifically, UV-B (280-320nm) and UV-A (320$400 \mathrm{~nm}$ ) irradiation depending upon the season, depth in the water and water turbidity, but also, dehydration due to daily tidal fluctuations. Consequently, these marine organisms require endogenous antioxidant protection 
against cell and organelle membrane damage (Aguilera et al., 2002).

In the PT test, no anticoagulant activity was found. However, the SPSG showed strong dosedependent anticoagulant activity in the aPTT test. To prolong the coagulation time to double baseline value in the aPTT, the required concentration of the SPSG was 2.5-fold higher than that of LMW heparin, a reference drug used in the treatment of thromboembolic diseases in recent years. These data are in agreement with several studies that clearly showed that the sulfated polysaccharides extracted from seaweeds exhibited anticoagulant activity as potent as heparin. However, the literature revealed that the relationships between anticoagulant activity and structure are not merely a consequence of their charge density. The structural basis of this interaction is complex because it involves naturally heterogeneous polysaccharides but depends on the distribution of sulfate groups and on monosaccharide composition. Thus, in addition to the content of the sulfate groups in polysaccharides, the positions of these groups in a monosaccharide residue also influenced the anticoagulant activity. Here, the SPSG has galactose-6-sulfate as observed in FT-IR, indicating that this sulfated residue is important for the anticoagulant activity of SPSG. In agreement with our results, Chaidedgumjorn et al. (2002) showed polysaccharides that were specifically desulfated at position C6 lost their anticoagulant activity, whereas desulfation on $\mathrm{C} 4$ did not affect the polysaccharide anticoagulant activity. This result suggests that sulfated polysaccharides from $C$. cupressoides may be used in anticoagulant therapy. Thus, more detailed studies are needed to elucidate the structural requirements for the interaction of SPSG with coagulation inhibitors and their target proteases.

In conclusion, we obtained a $11 \mathrm{kDa}$ sulfated polysaccharide (SPSG) from the seagrass Halodule wrightii composed mainly of galactose, glucose, and xylose. This polysaccharide showed antioxidant activity (CAT test), superoxide radical and DPPH scavenge, and also reducing power activity. It also showed potent anticoagulant activity in the APTT tests. With such strong concomitant antioxidant and anticoagulant activities, the SPSG was identified as a potential multipotent drug.

\section{Acknowledgements}

This study was supported by grants from $\mathrm{CNPq}$, MCT and CAPES. JMCS and DG are the recipient of a fellowship from CAPES and HR, ND-S are recipients of a fellowship from CNPq.

\section{References}

Aguilera J, Bischof K, Karsten U, Hanelt D, Wiencke C 2002. Seasonal variation in ecophysiological patterns in macroalgae from an Arctic fjord. II. Pigment accumulation and biochemical defence systems against high light stress. Mar Biol 141: 603-604.

Almeida-Lima J, Costa LS, Silva NB, Melo-Silveira RF, Silva FV, Felipe MBMC, Medeiros SRB, Leite EL, Rocha HAO 2010. Evaluating the possible genotoxic, mutagenic and tumor cell proliferation-inhibition effects of a non-anticoagulant, but antithrombotic algal heterofucan. J Appl Toxicol 30: 708-715.

Aquino RS, Landeira-Fernandez AM, Valente AP, Andrade LR, Mourão PA 2005. Occurrence of sulfated galactans in marine angiosperms: evolutionary implications. Glycobiology 15: 11-20.

Aquino RS, Grativol C, Mourão PAS 2011. Rising from the sea: correlations between sulfated polysaccharides and salinity in plants. PLOS ONE 6: e18862.

Barnham KJ, Masters CL, Bush AI 2004. Neurodegenerative diseases and oxidative stress. Nat Rev Drug Discov 3: 205-214.

Camara RBG, Costa LS, Fidelis GP, Nobre LTDB, DantasSantos N, Cordeiro SL, Costa MSSP, Alves LG, Rocha HAO 2011.Heterofucans from the brown seaweed Canistrocarpus cervicornis with anticoagulant and antioxidant activities. Mar Drugs 9: 124-38.

Costa LS, Fidelis GP, Cordeiro SL, Oliveira RM, Sabry DA, Câmara RBG, Nobre LTDB, Costa MSSP, AlmeidaLima J, Farias EHC, Leite EL, Rocha HAO 2010. Biological activities of sulfated polysaccharides from tropical seaweeds. Biomed Pharmacother 64: 21-28.

Chandini SK, Ganesan P, Bhaskar N 2008. In vitro antioxidant activities of three selected brown seaweeds of India. Food Chem 107: 707-713.

Chaidedgumjorn A, Toyoda H, Woo ER, Lee KB, Kim YS, Toida T, Imanari T 2002. Effect of (1->3)- and (1->4)linkages of fully sulfated polysaccharides on their anticoagulant activity. Carbohydr Res 337: 925-933.

Dietrich CP, Dietrich SM 1976. Electrophoretic behaviour of acidic mucopolysaccharides in diamine buffers. Anal Biochem 70: 645-647.

Dubois M, Gilles K, Hamilton JK, Rebers PA, Smith F 1956. Colorimetric method for determination of sugars, and related substances. Anal Chem 28: 350-356.

Farias EH, Pomin VH, Valente AP, Nader HB, Rocha HA, Mourão PA 2008. A preponderantly 4-sulfated, 3-linked galactan from the green alga Codium isthmocladum. Glycobiology 18: 250-259.

Hirst EL, Rees DA, Richardson NG 1965. Seed polysaccharides and their role in germination. A survey of the polysaccharide components of mustard seeds with special reference to the embryos. Biochem J 95: 453-8. 
Hu T, Liu D, Chen Y, Wu J, Wang S 2010. Antioxidant activity of sulfated polysaccharide fractions extracted from Undaria pinnitafida in vitro. Int J Biol Macromol 46: 193-198.

Jiao G, Yu G, Zhang J, Ewart HS 2011. Chemical structures and bioactivities of sulfated polysaccharides from marine algae. Mar Drugs 9: 196-223.

Magalhães KD, Costa LS, Fidelis GP, Oliveira RM, Nobre LTDB, Dantas-Santos N, Camara RBG, Albuquqerque IRL, Cordeiro SL, Sabry DA, Costa MSSP, Alves LG, Rocha HAO 2011. Anticoagulant, antioxidant and antitumor activities of heterofucans from the seaweed Dictyopteris delicatula. Int J Mol Sci 12: 3352-3365.

Mao W, Li H, Li Y, Zhang H, Qi X, Sun H, Chen Y, Guo S 2009. Chemical characteristic and anticoagulant activity of the sulfated polysaccharide isolated from Monostroma latissimum (Chlorophyta). Int $J$ Biol Macromol 44: 70-74.

Matsubara K, Matsuura Y, Bacic A, Liao M, Hori K, Miyazawa K 2001. Anticoagulant properties of a sulfated galactan preparation from a marine green alga, Codium cylindricum. Int J Biol Macromol 28: 395-399.

Mazumder S, Ghosal PK, Pujol CA, Carlucci M, Damonte EB, Ray B 2002. Isolation, chemical investigation and antiviral activity of polysaccharides from Gracilaria corticata (Gracilariaceae, Rhodophyta). Int J Biol Macromol 31: 87-95.

Nader HB, Lopes CC, Rocha HA, Santos EA, Dietrich CP 2004. Heparins and heparinoids: occurrence, structure and mechanism of antithrombotic and hemorrhagic activities. Curr Pharm Des 10: 951-966.

Pomin VH 2010. Structural and functional insights into sulfated galactans: a systematic review. Glycoconj $J$ 27: 1-12.

Pomin VH, Pereira MS, Valente AP, Tollefsen DM, Pavão MSG, Mourão PAS 2005. Selective cleavage and anticoagulant activity of a sulfated fucan: stereospecific removal of a 2-sulfate ester from the polysaccharide by mild acid hydrolysis, preparation of oligosaccharides, and heparin cofactor II-dependent anticoagulant activity. Glycobiology 15: 369-81.

Qi H, Zhang T, Hu R, Zhang K, Li Z 2006. In vitro antioxidant activity of acetylated and benzoylated derivatives of polysaccharide extracted from Ulva pertusa (Chlorophyta). Bioorg Med Chem Lett 16: 24412445.

Rocha HAO, Moraes FA, Trindade ES, Franco CRC, Torquato RJS, Veiga SS, Valente AP, Mourão PAS, Leite EL, Nader HB, Dietrich CP 2005. Structural and hemostatic activities of a sulfated galactofucan from the brown alga Spatoglossum schroederi. An ideal antithrombotic agent? J Biol Chem. 280: 4127841288.

Simpson AGB, Roger AJ 2004. The real kingdoms of eukaryotes. Curr Biol 14: 693-696.

Souza MCR, Marques CT, Dore CMG, Silva FRF, Rocha HAO, Leite EL 2007. Antioxidant activities of sulfated polysaccharides from brown and red seaweeds. $J$ Appl Psychol 19: 153-160.

Zhang Z, Zhang Q, Wang J, Song H, Zhang H, Niu X 2010. Chemical modification and influence of function groups on the in vitro-antioxidant activities of porphyran from Porphyra haitanensi. Carbohyd. Polym 79: 290-295.

Wang J, Zhang Q, Zhang Z, Li Z 2008. Antioxidant activity of sulfated polysaccharide fractions extracted from Laminaria japonica. Int J Biol Macromol 42: 127132.

\section{*Correspondence}

Hugo Alexandre de Oliveira Rocha

Laboratório de Biotecnologia de Polímeros Naturais, Departamento de Bioquímica, Centro de Biociências, Universidade Federal do Rio Grande do Norte

Av. Salgado Filho S/N, Natal-RN, Brazil

hugo@cb.ufrn.br

Tel.: +558432153416

Fax: +55 8432119208 